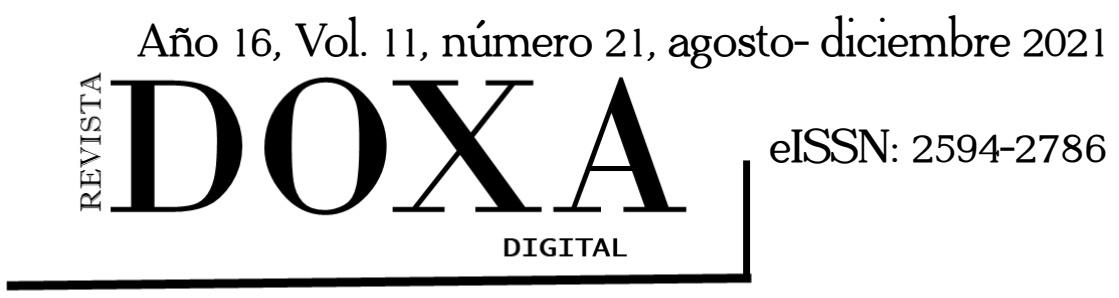

Sección: Ciencias Sociales

Recibido: Agosto 2019

Aceptado: Febrero 2021

DOI: $10.52191 /$ rdojs.2021.145

Pág.: 35-51

\title{
La Historia de Vida como técnica de recolección de datos cualitativos para estudios en Ciencias Sociales
}

\author{
Life Story as a qualitative data collection technique for Social Science studies
}

\author{
Carlos Jesús González Macías *, Ulises Mendoza Arvizo **, y Luis Adrián Lozoya Muñoz ***
}

\section{RESUMEN}

Se aproxima a la historia de vida como técnica de recolección de datos cualitativa y sus aportaciones a las ciencias sociales, mediante un análisis para determinar su papel particular en estudios en ciencias sociales. Esta técnica brinda una mejor comprensión de la historia de una persona, basada en experiencias dentro y fuera de su contexto, conceptualizando una visión para un adecuado estudio que implica una interacción directa con personas. Se considera a la historia de la vida como una técnica confiable para recolectar datos que conduzcan a resultados notables que brinden un impacto relevante para los estudios en ciencias sociales

PALABRAS CLAVE: Investigación cualitativa; Historia de vida; Técnicas de recolección de datos; Ciencias sociales.

\section{ABSTRACT}

The life story as a qualitative data collection technique and its contributions to social sciences is approached, through an analysis in order to determine its particular role in social sciences studies. This techinique provide a better comprehension of a person's story based on experiences in and out of its context, by conceptualizing a vision that for an adequate study that implies direct interaction with persons. The life story is considered as a reliable technique for data collection, leading to remarkable results that deliver a relevant impact to social sciences studies.

KEY WORDS: Qualitative research; Life story; Data collection techniques; Social sciences

*Autor para correspondencia. Doctor en Ciencias Administrativas por la Universidad Autónoma de Ciudad Juárez. Coordinador del Centro de Investigación en Ciencias Administrativas y Estudios Empresariales y Editor en Jefe de NovaRUA Revista Universitaria de Administración. Contacto cgonzalez@uacj.mx

** Doctor en Ciencias Administrativas. Coordinador del Programa de Administración del Instituto de Ciencias Sociales y Administración de la Universidad Autónoma de Ciudad Juárez. Contacto: ulises.mendoza@uacj.mx

*** Maestro en finanzas por la Universidad Autónoma de Chihuahua. Profesor de tiempo completo en la licenciatura en Finanzas de la Universidad Autónoma de Ciudad Juárez. Contacto: luis.lozoya@uacj.mx 
Año 16, Vol. 11, número 21, agosto-diciembre Sección: Ciencias Sociales

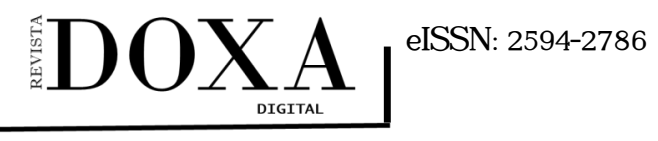

DOI: $10.52191 /$ rdojs.2021.145

Pág.: $35-51$
Carlos Jesús González, et al.....

La Historia de Vida como técnica ...

\section{Introducción a la investigación cualitativa en ciencias sociales}

Al considerar a la investigación como un componente fundamental del conocimiento humano se le otorga su esencial importancia, y hablando en términos generales se le ha podido conceptualizar como aquel proceso donde convergen e interrelacionan, por una parte, un sujeto cognoscente (quien conoce un objeto de conocimiento), y por la otra, un objeto de conocimiento (aquello que el sujeto cognoscente conoce). De esta convergencia e interrelación emana como resultado el denominado conocimiento. Como referencia epistemológica, el conocimiento es un enfoque interpretativo y subjetivo que se da a través de la observación e interpretación, estas sesgadas por los estilos de pensamiento y experiencias, alude Corona (2018). Así, ese nuevo producto, el conocimiento, constituye al mismo tiempo la interrelación y el resultado de ella. En otras palabras, el conocimiento sería la acción subjetiva que lo produce, así como al producto obtenido de ella.

La humanidad ha sido distinguida por su habilidad para formular interrogantes que le permitan entender y esclarecer todos los sujetos, objetos y sucesos existentes en su entorno social, impulsándola a analizar sus códigos y relaciones, y de esa manera ir descubriendo las causas que originan las cosas existentes a su alrededor, en relación con aquellas respuestas buscadas a esas interrogantes formuladas. Resulta entonces inconcebible el pensar que no exista una simbiótica relación entre sujeto y objeto dentro del conocimiento.

Si acaso existe una fuerza impulsora a lo que se conoce como ciencia, esta sería entonces esa simbiótica interacción que mantienen dichos objeto y sujeto, esa sinergia característica en ese mencionado proceso de interacción. Razón por la cual, este siempre nuevo (independiente de su edad cronológica) y renovado enfoque cualitativo busca interesarse por la realidad social humana y construirla conceptualmente, a través del conocimiento.

La investigación en las ciencias sociales con enfoque cualitativo se ha venido desarrollando desde hace cuatro décadas, el impulso de esta investigación yace en la necesidad de un cambio de paradigma en el que la mayoría fue formada, aluden Arias y Betancurth (2015). Además, la investigación cualitativa posee una esencia netamente humanista, en aras de entender la realidad social desde una óptica del estado ideal de las cosas, sobresaliente como una concepción explicativa, que ayuda a explicar, la evolución y asimilación del orden social. La investigación cualitativa transciende por su forma de trabajar intelectual, la cuestión del ser y el hacer, argumenta De la Cuesta (2015). El enfoque cualitativo distingue en los estudios sociales los fenómenos producidos por la 
Año 16, Vol. 11, número 21, agosto-diciembre Sección: Ciencias Sociales

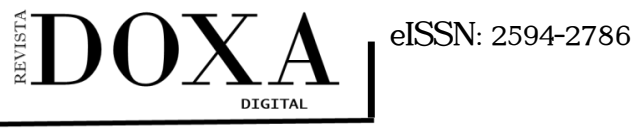

DOI: $10.52191 /$ rdojs.2021.145 Pág.: 35-51
Carlos Jesús González, et al.....

La Historia de Vida como técnica ...

interacción constante entre los individuos que la conforman, y donde los datos recolectados emanan de la vida cotidiana y su propio sentido común, así como de las explicaciones y reconstrucciones efectuadas por el individuo para vivir y sobrevivir diariamente (Ruiz, 2012), estableciendo una realidad identificada comparada con el estado ideal mencionado. Esta búsqueda del conocimiento se concentra en los fenómenos sociales dentro de su contexto, vivencia e interpretación, sugieren Troncoso y Amaya (2017). "Los métodos cualitativos acentúan las diversas formas en las que podemos situarnos para dar respuesta adecuada a las situaciones concretas que se irán demarcando en el proceso investigativo" (Chárriez, 2012, p. 50).

La investigación cualitativa en los estudios en ciencias sociales se enfoca primordialmente en formular explicaciones que interpreten acciones, lenguajes, signos, expresiones, percepciones, actitudes, entre otros, que resulten relevantes para el investigador, situándolo en una estrecha correspondencia con la amplitud del contexto social para un mejor entendimiento de él. En ese sentido, este investigador en ciencias sociales conduce su estudio en contextos que le son naturales, tal y como los encuentra en la naturaleza, más que someterlos a una reconstrucción o modificación (Taylor, 1998), teniendo como objetivo la comprensión y la interpretación de acontecimientos dentro de la vida humana y social, persiguiendo una finalidad de interés práctico en aras de situar y alinear el actuar humano con su realidad subjetiva. Por ello, se considera que los acontecimientos sociales y los individuos son los propulsores de las investigaciones, aluden Barba, Barba y González (2015).

Por lo anterior, la investigación cualitativa en ciencias sociales busca comprender la individualidad singular que caracteriza a los individuos y a los grupos sociales, dentro de su contextualización histórica y cultural, explorando la realidad tal como otros la experimentan, interpretando sus propios significados, sentimientos, creencias y valores. Es así como esta investigación cualitativa sigue directrices de investigación flexibles y holísticas sobre las personas, organizaciones o grupos, estudiándolos como un todo, cuya riqueza y complejidad constituyen la esencia de lo investigado (Berríos, 2000).

\section{La investigación cualitativa en ciencias sociales y la historia de vida}

Para el enfoque cualitativo en ciencias sociales, el interactuar con los individuos dentro de su contextualización social es su razón de ser, al absorber e interpretar la significancia de sus acciones, además de todo conocimiento poseído de sí mismos y de su realidad con la que interactúan, pretendiendo una aproximación general y científica en relación a los aconteceres sociales deriva- 
Año 16, Vol. 11, número 21, agosto-diciembre Sección: Ciencias Sociales

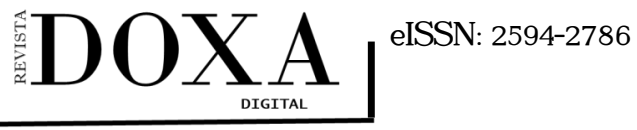

DOI: $10.52191 /$ rdojs.2021.145 Pág.: 35-51
Carlos Jesús González, et al.....

La Historia de Vida como técnica ...

dos de la peculiar fenomenología humana producidos por estos, con el afán de identificarlos, explorarlos, explicarlos, y comprenderlos desde una óptica teórica interpretativa.

Para este cometido, la historia de vida resulta ser una técnica cualitativa de recolección de datos que pretende entender al contexto y los procesos sociales desarrollados dentro de él, a partir del bagaje experiencial del individuo. "La historia de vida puede establecer un puente, una doble relación, entre interés y desinterés, condicionantes e indeterminaciones sociales" (Veras, 2010, p. 143). Así mismo, se debe tener en cuenta que también se pueden obtener valiosos relatos experienciales de un grupo o de una organización, ya que es uno de los métodos cualitativos más puros y potentes para conocer como las personas interactúan en el mundo social que les rodea (Hernández, 2009).

De esta manera, la historia de vida puede ser definida como todo aquél relato que cuenta la vivencia experiencial de un individuo, o bien un grupo. Es una construcción individual y autobiográfica, donde el investigador estimula el contenido del relato, a manera que exprese la muy personal percepción del informante, en relación a los diversos recuerdos referentes a aquellas situaciones que habrá vivido (Pourtois, 2005). Es la singularidad de dicho individuo o grupo la que se debe preponderar como reveladora de una específica vivencia dentro de su contexto social. Para entender o apreciar del concepto, "...es posible remitirse a que la historia de vida es la forma en que una persona narra de manera profunda las experiencias de vida en función de la interpretación que ésta le haya dado a su vida y el significado que se tenga de una interacción social” (Chárriez, 2012, p. 53).

Así, la historia de vida se define también como:

El termino amplio que recubre una cantidad de relatos respeto de hechos no registrados por otro tipo de documentación, o cuya documentación se desea completar. Recogida por medio de entrevistas de variadas formas, ella registra la experiencia de un individuo o de diversos individuos de una misma colectividad (Veras, 2010, p. 144).

La notable importancia de la técnica de la historia de vida forma parte de la actual "revalorización del actor social (individual y colectivo), no reducible a la condición de dato o variable (o a la condición de representante arquetípico de un grupo), sino caracterizado como sujeto de configuración compleja y como protagonista de las aproximaciones que desde las ciencias sociales se quiere hacer de la realidad social" (Pujadas, 2000, p. 127). En ese sentido, "la historia de vida, como investigación cualitativa, busca descubrir la relación dialéctica, la negociación cotidiana entre 
Año 16, Vol. 11, número 21, agosto-diciembre Sección: Ciencias Sociales

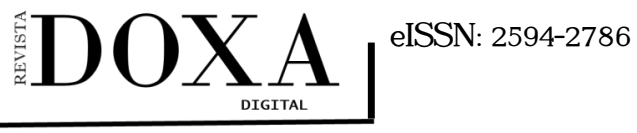

DOI: $10.52191 /$ rdojs.2021.145

Pág.: 35-51
Carlos Jesús González, et al.....

La Historia de Vida como técnica ...

aspiración y posibilidad, entre utopía y realidad, entre creación y aceptación" (Chárriez, 2012, p. $50)$.

Así entonces, la historia de vida es toda narración del bagaje experiencial de vida de un individuo, un grupo o una organización, convertido en un documento autobiográfico realizado por un investigador que estimula la memoria del ente entrevistado. A través de esta técnica se realiza una lectura del acontecer social de la vida de un individuo, buscando en la memoria colectiva en su actuar cotidiano. No busca entonces una simple narración que relate grandes aconteceres, vistos desde cierto ángulo, sino de una abstracción particular de la historia desde el muy personal ángulo de precepción del informante, lo que enriquece y brinda significancia al conocimiento acerca de la realidad social. En las historias de vida se requiere del sujeto narre sus vivencias personales, a manera que refleje todas aquellas vivencias que, para él, hayan marcado su vida de manera significativa.

\section{La práctica de los estudios en ciencias sociales a través de la historia de vida}

Las historias de vida constituyen una técnica cualitativa de recolección de datos que provee información relevante sobre acontecimientos, usos y costumbres, explicando cómo es la persona, observando sus acciones en su rol humano al ser actor participante en el devenir social, reconstruyendo aconteceres vividos y transmitiendo su bagaje de experiencia de vida. Chárriez, (2012, p. 53) comenta al respecto:

"[...] incluye la información acumulada sobre la vida del sujeto: escolaridad, salud, familia, entre otros, realizada por el investigador, quien actúa como narrador, transcriptor y relator. Éste, mediante entrevistas sucesivas obtiene el testimonio subjetivo de una persona de los acontecimientos y valoraciones de su propia existencia. Se narra algo vivido, con su origen y desarrollo, con progresiones y regresiones, con contornos sumamente precisos, con sus cifras y significado.

La recopilación de estas narraciones a través de la historia de vida no desempeña solamente el exclusivo papel de instrumento de recolección de datos cualitativos que rellenaría los huecos que dejan la investigación documental o la etnografía (Pujadas, 2000), sino que estas recogen a profun-

didad los recuerdos almacenados en la memoria que, como una precondición humana, existe la posibilidad del olvido de una porción, grande o pequeña, de lo sucedido, y donde el investigador reali- 
Año 16, Vol. 11, número 21, agosto-diciembre Sección: Ciencias Sociales

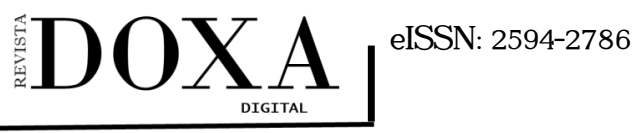

DOI: $10.52191 /$ rdojs.2021.145

Pág.: 35-51
Carlos Jesús González, et al.....

La Historia de Vida como técnica ...

za la importante labor de estimular la memoria del entrevistado a manera de evitar, lo más posible, tal situación. Birulés (1995, p. 9) comenta al respecto:

"[...] es absolutamente imposible vivir sin olvidar... el sentido no histórico y el histórico son igualmente necesarios, pero cuando nos referimos (...) a la memoria histórica del pasado, habrá que adelantar que difícilmente se puede olvidar lo que apenas ha sido recibido o transmitido".

En ese sentido, la manera de relacionarse personal e intelectualmente los dos interlocutores es medular para la construcción de las narraciones con finalidad de historias de vida, pues la interpretación del investigador, su concepción y predisposición cultural, además de su intelectualidad, se encuentran con las del entrevistado. Al realizar esta interlocución, el escuchar adecuadamente implica una minuciosa y especial atención a aquellos silencios que se pudieran suscitar, a manera de renunciar de cierta forma a la excesiva valoración de la opinión vertida por alguna de las partes. "Esto no significa convertirse en un observador neutral sino precisamente lo opuesto; ser un buen oyente siempre requiere simpatía" (Muratorio, 2005, p. 131).

La historia de vida, como técnica cualitativa pretende desarrollar un proceso de interpretación, observando desde la personal perspectiva de los individuos, pero esta interpretación debe tener características epistemológicas realistas, por ello la importancia de verse también como una observación, argumentan Aguirre y Jaramillo (2015). Los individuos y observaciones están continuamente interpretándose y definiéndose en diferentes situaciones (Chárriez, 2012). De acuerdo con Pujadas (2000, p. 139), existen tres elementos esenciales de estrategia cuando se conducen entrevistas con orientación de historia de vida:

1. Se trata de entrevistas en profundidad abiertas (esto es, no estructuradas) en las que la labor del investigador consiste básicamente en estimular al informante para que siga el hilo de su narración, procurando no interrumpirle y manteniendo la atención para orientarle en los momentos de lapsus de memoria.

2. Esta labor de orientación se debe apoyar en el uso de cuantos documentos personales (cartas, fotografías, diarios personales) que estén a mano durante la entrevista; por ello es tan importante que el lugar elegido para este intercambio sea el domicilio de la persona.

3. Para apoyar la narración del informante y, a la vez, para garantizar la máxima exhaustivi- 
Año 16, Vol. 11, número 21, agosto-diciembre Sección: Ciencias Sociales

DOXA
DOI: $10.52191 /$ rdojs.2021.145

Pág.: $35-51$
Carlos Jesús González, et al.....

La Historia de Vida como técnica ...

dad posible del relato, es imprescindible que el investigador tenga transcritas las entrevistas anteriores y sistematizadas en los cuatro archivos sugeridos: literal, temático, cronológico y por personas. Lo anterior, debido a que el investigador tiene el conocimiento de que lo publicado de esa narración serán sometidas a verificación, sino porque esta narración es una realidad filtrada por su interpretación, comenta Martínez (2015).

Cornejo, Rojas y Mendoza (2008) proponen un interesante modelo de trabajo para el diseño de investigaciones con relatos de vida que contempla las siguientes etapas:

1. Momento preliminar. Antes de la recolección del primer relato, el investigador debe realizar dos elecciones ineludibles: el tema y el ángulo de abordaje del mismo, respondiendo algunas cuestiones suscitadas: ¿Por qué la elección del tema? ¿Por qué investigarlo? ¿Para qué investigarlo?, ¿El interés surge de una experiencia personal? ¿Cuál? Asimismo, debe hacerse una revisión crítica de la literatura científica pertinente al tema con el fin de profundizar en la comprensión del objeto de estudio. El manejo de fuentes más recientes a lo largo de la investigación permite la emergencia de nuevas pistas dignas de consideración.

2. Contactos, negociaciones y contratos. En esta fase, los cuestionamientos éticos se vuelven fundamentales, cruzándose con los científicos. Se trata de definir y aplicar los criterios de inclusión y exclusión de los participantes, delimitar los narradores que van a intervenir y entregarles la información sobre los objetivos y el contenido de la investigación, así como los procedimientos que va a suponer su participación. Asimismo, se aboga por consentimiento informado y por la libertad para dejar la investigación en el caso que se desee. El conocimiento de los investigadores por parte de los participantes facilita la transparencia y acercamiento en este tipo de trabajos.

3. Recolección de los relatos mediante la entrevista. Los relatos de vida son siempre construcciones, versiones de la historia que un narrador o sujeto interpelado en su historia relata al investigador o narratorio particular utilizando para ello la entrevista. Para el citado autor son dignos de consideración aspectos, como el número, duración, ritmo y conducción de las entrevistas, así como la transcripción de los relatos lo más fidedignamente posible, con toda su riqueza (lenguaje, lapsus, modismos, entre otros). La utilización de un cuaderno de campo posibilita realizar un mejor seguimiento del proceso y preparar el material para análisis. 
Año 16, Vol. 11, número 21, agosto-diciembre Sección: Ciencias Sociales

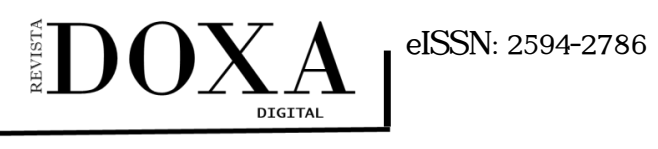

Pág.: 35-51
Carlos Jesús González, et al.....

DOI: $10.52191 /$ rdojs.2021.145

La Historia de Vida como técnica ...

4. Análisis de los relatos. La lógica y la metodología de análisis de los relatos debe estar en función, por un lado, del objeto de estudio, y por otro, del tipo de resultados que se deseen obtener; es decir los métodos de análisis deben adaptarse a ellos y nunca al revés. Por ello, la interpretación de los resultados siempre será cualitativa, no importa si son numéricos o estadísticos; al momento de la interpretación de la información esta se categoriza por medio de una acción cualitativa menciona Paramo y Otálvaro (2006).

La investigación cualitativa a través de la historia de vida es en esencia una explicación de fenómenos sociales que exige cuatro habilidades procedimentales en el investigador: observar, escuchar, comparar y escribir, tal como es propuesto por Sanmartín (2003) para la práctica de la investigación cualitativa (Ver figura 1):

Figura 1. Cuatro habilidades procedimentales del investigador

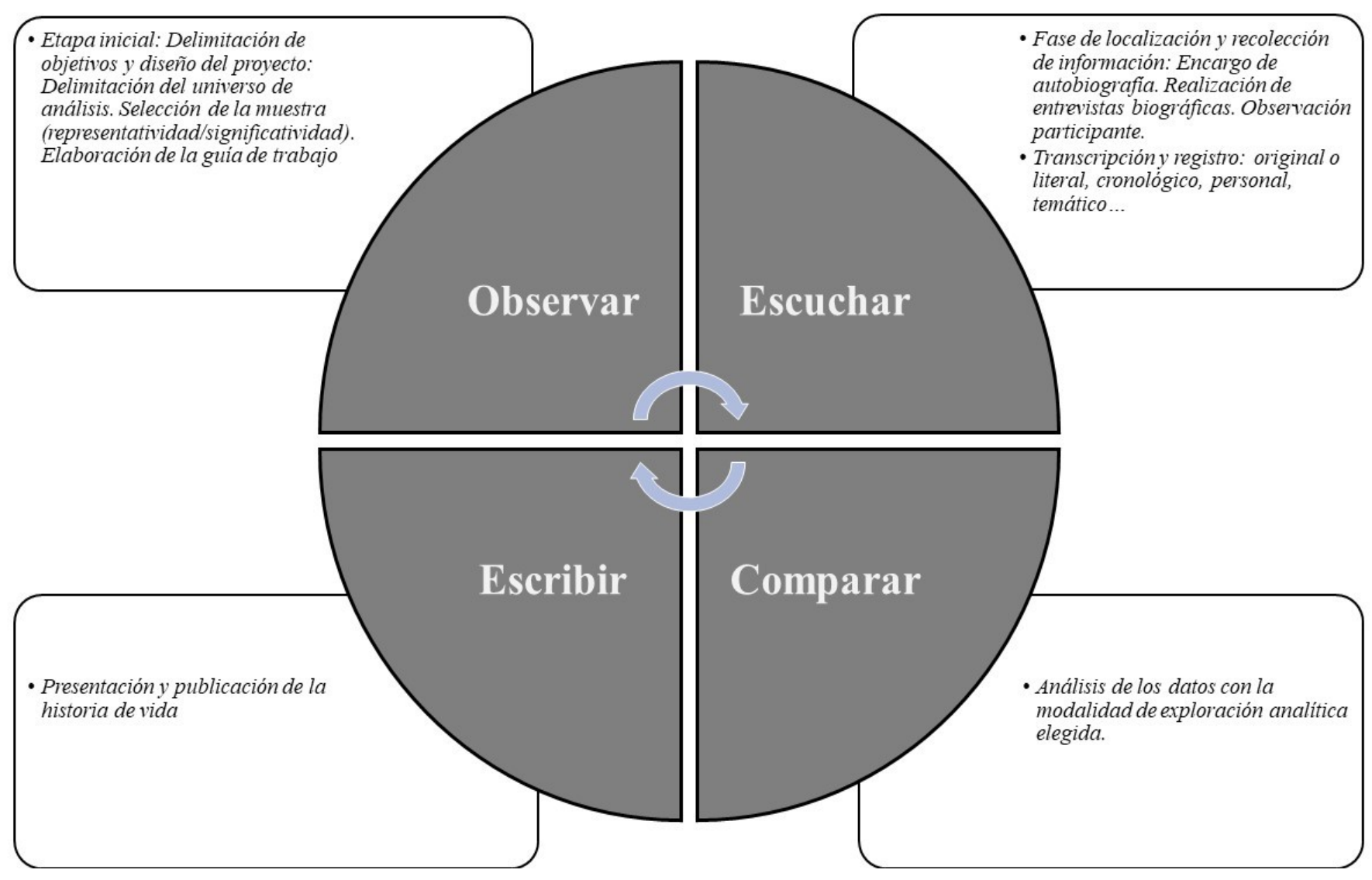

Fuente: Elaboración propia con base en Sanmartín (2003). 
Año 16, Vol. 11, número 21, agosto-diciembre Sección: Ciencias Sociales

DOXA
DOI: $10.52191 /$ rdojs.2021.145

Pág.: 35-51
Carlos Jesús González, et al.....

La Historia de Vida como técnica ...

\section{La persona como fuente básica de los estudios sociales a través de la historia de vida: su identidad, sus recuerdos y su interacción social}

La historia de vida motiva al investigador a que no se incurra en una separación entre la cultura de los individuos que la crean y desarrollan, la viven día a día y en ocasiones hasta la desafían, sino que se proporcione un entendimiento de cómo esa cultura, la estructura que se le fue proporcionada por la sociedad y los procesos históricos devenidos de ella ejercen una influencia directa e inseparable sobre las vidas de los individuos. "Más específicamente, historias de vida también pueden revelarnos el desafío y la transgresión de supuestas pautas culturales compartidas" (Muratorio, 2005, p. 134). Lo anterior toma sentido debido a que el enfoque cualitativo posee una visión humanista abierta al individuo y al fenómeno social que evoca y provoca, valorando de manera profunda al ser humano, encontrándose con él y enriqueciéndose a partir de ese encuentro (Bonilla, 2005).

La principal fuente de la historia de vida es el individuo y los nutrientes que provee su testimonio, proporcionados por una individualidad única de un sujeto histórico donde confluyen sus dimensiones psicológicas y contextuales que generan su muy peculiar y singular forma de construir y relatar toda su experiencia vivida, siempre en clara relación con la situación presente y los proyectos (Sanz, 2005). Pujadas (2000, p. 141) menciona que se debe tener en cuenta la singularidad y la individualidad de las personas, obligando ello a no desestimar las siguientes situaciones:

1. Es muy difícil encontrar un buen informante, esto es, que sea un buen narrador -alguien con capacidad expresiva, con un discurso ameno y comprensible y sin demasiados lapsus de memoria y que, por otro lado, no sea un fabulador que mezcle en su memoria fantasía con realidad. De la calidad del informante seleccionado dependerá que el relato sea lo más completo posible, sincero, genuino y crítico.

2. Hay un requisito fundamental, que el informante quiera y pueda dedicar todo el tiempo que comporta componer entera una historia de vida, sometiéndose a las numerosas sesiones de las que irá surgiendo el relato biográfico en que se basará el texto final o historia de vida. Esta segunda premisa, la disponibilidad del informante y su constancia, no depende solamente de él sino de las circunstancias culturales y sociales generales que definen la relación intersubjetiva entre éste y el investigador -éste ha de tener la capacidad de convicción y ha de ganarse la confianza y el deseo de colaboración del sujeto, que puede desconfiar del uso que pueda hacerse de un material tan privado. 
Año 16, Vol. 11, número 21, agosto-diciembre Sección: Ciencias Sociales

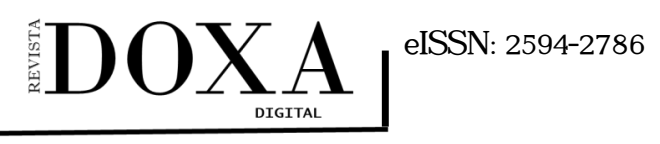

DOI: $10.52191 /$ rdojs.2021.145

Pág.: 35-51
Carlos Jesús González, et al.....

La Historia de Vida como técnica ...

3. La elección del informante biográfico requiere de la adecuación del perfil de la persona, como estudio de caso, al tipo de testimonio que se adapte a los objetivos de nuestra investigación. El testimonio que se busca ha de cumplir de alguna manera el requisito de ser "representativo" de todo el grupo social que se ha estudiado, a pesar de los rasgos de irreductible especificidad que cualquier estudio de caso muestra.

La intrínseca individualidad de la persona se relaciona de manera directa al contexto social en el cual interactúa, al espacio en donde se desenvuelve dicha interacción y al tiempo que le toma llevar a cabo la interacción, al momento de narrar sus experiencias de vida. Las experiencias vividas en el pasado y el aprendizaje recordado que les ha sido enseñado influyen de una manera vigorosa. "Desde nuestra situación actual juzgamos el pasado y nos apoyamos en representaciones colectivas e interpretaciones, en principio ajenas a nosotros como personalidades individuales pero que, sin embargo, configuran la racionalización que de nuestra vida y del contexto hacemos" (Sanz, 2005, p. 106).

Aunado a la importancia que caracteriza al ser humano propio del investigador al abordar a una persona "...la historia de vida de alguien corresponde a una dimensión íntima y subjetiva que el investigador necesita respetar bajo la pena de 'violar' el sujeto investigado, destaca el papel activo del investigador a medida en que su criterio, decisión y autonomía constituyen la base fundamental para la buena aplicación de la técnica" (Veras, 2010, pág. 144).

\section{Potencialidades de los estudios sociales a través de la historia de vida}

Las historias de vida proveen un amplio marco de interpretación en torno a los fenómenos sociales, por las experiencias humanas se manifiestan en todos aquellas narraciones individuales y personales, priorizando las explicaciones individuales de las acciones al momento de interactuar más que a los métodos que filtran y ordenan las respuestas en categorías conceptuales de conductas sociales predeterminadas (Jones, 1983).

Según Ruíz (2003), las potencialidades más representativas de la historia de vida, como técnica de recolección de datos, y que pueden ser aplicadas a disciplinas como las ciencias sociales, son las siguientes:

1. Captar la totalidad de una experiencia biográfica, totalidad en el tiempo y en el espacio, 
Año 16, Vol. 11, número 21, agosto-diciembre Sección: Ciencias Sociales

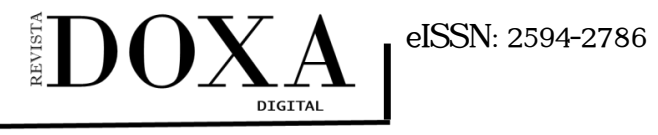

DOI: $10.52191 /$ rdojs.2021.145

Pág.: 35-51
Carlos Jesús González, et al.....

La Historia de Vida como técnica ...

desde la infancia hasta el presente, desde el yo íntimo a todos cuantos entran en relación significativa con la vida de una persona. Incluye las necesidades fisiológicas, la red familiar, las relaciones de amistad, la definición personal de la situación, el cambio personal y el cambio de la sociedad ambiental, los momentos críticos y las fases tranquilas, la inclusión y la marginación de un individuo en su mundo social circundante.

2. Captar la ambigüedad y el cambio. Lejos de una visión estática e inmóvil de las personas y de un proceso vital lógico y racional, la historia de vida intenta descubrir todos y cada uno de los cambios acaecidos a lo largo de su vida de la persona, las ambigüedades, faltas de lógica, dudas, contradicciones, vuelta atrás que se experimentan a lo largo de los años.

3. Captar la visión subjetiva con la que uno mismo se ve a sí mismo y al mundo, cómo interpreta su conducta y la de los demás, cómo atribuye méritos e impugna responsabilidades a sí mismo y a los otros. Tal visión revela la negociación que toda vida requiere entre las tendencias expresivas de la persona y las exigencias de racionalidad para acomodarse al mundo exterior.

4. Descubrir las claves de interpretación de fenómenos sociales de ámbito general e histórico que sólo encuentran explicación adecuada a través de la experiencia personal de los individuos concretos.

Los puntos anteriores, "permiten al investigador en ciencias sociales penetrar el universo reflejado en la transcripción de los relatos en la elaboración de historias de vida y el uso de los documentos personales, remitiéndose a un campo transdisciplinar en el que confluyen las corrientes humanistas de diferentes disciplinas: la historia social, la sociología, la psicología y la antropología social" (Pujadas, 2000, p. 127).

Además, el considerar que las historias y los textos que ellas producen desarrollan una identidad social propia en el presente resulta primordial. Nuevas concepciones y significancias se generan durante el proceso de narrarse en repetidas ocasiones, así como también cuando las generaciones más recientes, dentro de instituciones de educación formal, las leen. Es así que "...los investigadores sociales asumen la responsabilidad de buscar una voz que pueda cruzar la barrera cultural y se dirija tanto a audiencias académicas como no-académicas" (Muratorio, 2005, p. 134). 
Año 16, Vol. 11, número 21, agosto-diciembre

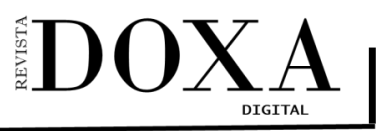

Sección: Ciencias Sociales

DOI: 10.52191/rdojs.2021.145

Pág.: 35-51
Carlos Jesús González, et al.....

La Historia de Vida como técnica ...

Los estudios sociales pueden apoyarse en lo estipulado por Pujadas (2000, p. 140-141), quien menciona que la edición de una historia de vida, elaborada a partir de relatos, supone básicamente:

1. Ordenar la información cronológica y temáticamente,

2. Recortar las digresiones y reiteraciones,

3. Ajustar el estilo oral del informante lo mínimo posible para que sea aceptable por éste,

4. Introducir notas a lo largo del texto que contextualicen y/o remitan a otras partes del texto,

5. Introducir, eventualmente, el testimonio de aquellas personas del universo familiar o social del informante que nos puedan permitir calibrar y dar perspectiva a la narración principal,

6. Realizar una introducción metodológica donde debemos explicitar todas las circunstancias del proceso de elaboración de la historia de vida, desde el primer contacto con el informante hasta la finalización del texto, y

7. Es tan recomendable, como poco frecuente, que el investigador realice, al final del texto, una interpretación del significado de la historia de vida editada en el contexto de los objetivos temáticos y de la perspectiva teórica que han guiado la investigación.

\section{Limitaciones metodológicas de la historia de vida}

Las limitaciones metodológicas en la investigación social “....surgen de la propia naturaleza de la oralidad y los documentos materiales de vida, de la interacción investigador-informante, y de la esencia de la memoria" (Sanz, 2005, p. 111). Las limitaciones de esta técnica más representativas pudieran ser:

1. La falta de coraje del entrevistador. Considerar a la historia de vida como una técnica capaz de conducir la incursión en aguas, profundas o no, o de sentir el miedo de acercarse al escenario para ver mejor aquello que los focos de luz nos permiten aprender de los movimientos de la bailarina (la vida)- es un acto de coraje a ser emprendido por el investigador (Veras, 2010, p. 150). La entrevista es un dialogo o interacción entre el investigador y los participantes, aluden Moscoso y Díaz (2018). Por ello, la dificultad del abordaje y la falta de 
Año 16, Vol. 11, número 21, agosto-diciembre Sección: Ciencias Sociales

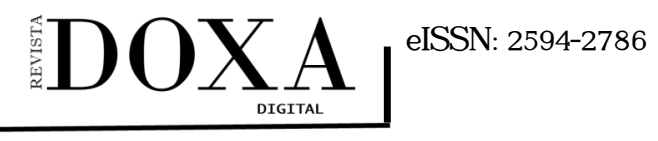

DOI: 10.52191/rdojs.2021.145

Pág.: 35-51
Carlos Jesús González, et al.....

La Historia de Vida como técnica ...

oficio son obstáculos para el entrevistador, las habilidades y conocimiento con los que debe contar para comunicar los hechos o relatos no son fáciles de adquirir, argumenta Merlinsky (2006).

2. La memoria selectiva del entrevistado. Es el individuo, con su subjetividad, quien selecciona unas vivencias, silencia otras y quien, en definitiva, organiza el discurso. Sin embargo, la autonomía del relato individual es limitada, pues viene condicionada por unos moldes culturales, que organizan tanto las estructuras narrativas como los contenidos y los valores que se vehiculan a través del relato (Pujadas, 2000, p. 149).

3. La falta de ética por parte del entrevistador. Indudablemente, uno de los aspectos básicos al realizar una investigación cualitativa es que debe adoptar dos dimensiones éticas fundamentales: a) una ética procedural, que implica la búsqueda de la aprobación por parte de un comité de expertos autorizados (comité de ética) para el desarrollo de la investigación; y b) una ética en la práctica, que alude a los desafíos que día a día impone la misma investigación (Chárriez, 2012, p. 59).

De las tres limitantes descritas anteriormente, la que requiere un tratamiento aún más profundo en investigación, es aquella referente a la ética. Es por esto por lo que Exequiel Emanuel, (citado en Botto, 2011), propuso siete requerimientos básicos para evaluar aspectos éticos en el marco de las investigaciones. Estos elementos se describen a continuación:

1. Valor científico o social: Para que una investigación sea ética debe tener valor, es decir, sus resultados debieran promover una mejoría en la salud o en las condiciones de vida de las personas, por ejemplo, a través de una intervención psicosocial o un tratamiento para una determinada enfermedad.

2. Validez científica: Un estudio pensado éticamente debe estar planificado a base de una metodología rigurosa que conduzca a resultados válidos. Este es un punto especialmente importante porque incorpora la ética dentro de los factores intrínsecos a cualquier metodología.

3. Selección equitativa de los participantes: La determinación de los sujetos que participarán en el estudio debe considerar los objetivos de la investigación, destacando cuáles serán los 
Año 16, Vol. 11, número 21, agosto-diciembre Sección: Ciencias Sociales

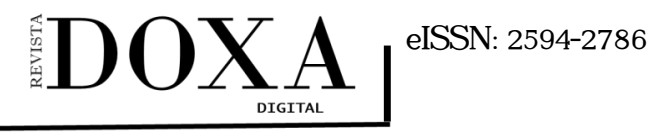

DOI: $10.52191 /$ rdojs.2021.145

Pág.: 35-51
Carlos Jesús González, et al.....

La Historia de Vida como técnica ...

criterios de inclusión y exclusión de tal manera que la selección esté comandada por un juicio científico más allá de las vulnerabilidades o el estigma social.

4. Proporción favorable del riesgo-beneficio: La investigación con personas debe considerar siempre el análisis cuidadoso de los riesgos y beneficios que puede implicar, especialmente si se trata de estudios que requieran de alguna intervención, farmacológica o psicoterapéutica. De esta manera, la investigación sólo podrá justificase cuando los riesgos potenciales para los sujetos individuales y para la sociedad se maximizan y los beneficios potenciales son proporcionales o exceden a los riesgos.

5. Revisores independientes: Dado los posibles conflictos de intereses de los investigadores, se sugiere contar con instancias de evaluación integradas por personas autorizadas que sean independientes al estudio y que puedan decidir sobre su desarrollo con objeto de evitar distorsiones en el diseño y salvaguardar la responsabilidad social.

6. Consentimiento informado: Es uno de los aspectos indiscutibles en cualquier investigación. Su propósito es otorgar el control de los sujetos respecto a su incorporación o retiro del estudio y asegurar su participación, en la medida que se respeten sus creencias, valores e intereses.

7. Respeto a los participantes potenciales o a los inscritos: La preocupación ética acerca de los participantes no finaliza cuando se firma el consentimiento. En cualquier estudio es necesario considerar permanentemente el respeto por las personas, su privacidad y el derecho de cambiar de opinión respecto a su participación en la investigación, recibiendo todo el apoyo y las atenciones que sean necesarias.

En resumen, tal como lo plantea Botto (2011), la aproximación ética propia de la investigación cualitativa en ciencias sociales de ninguna manera puede ser dimensionada únicamente desde una óptica externa, como lo sería el depender de los veredictos de una comisión ajena al proceso, sino que por el contrario debe dimensionarse como un elemento integrante de los estudios sociales, es decir, la ética como elemento esencial de su metodología. 
Año 16, Vol. 11, número 21, agosto-diciembre Sección: Ciencias Sociales

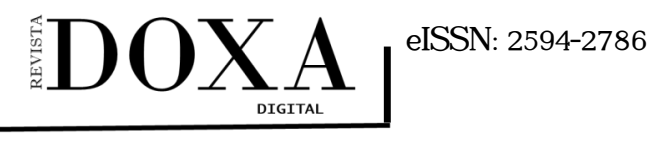

DOI: $10.52191 /$ rdojs.2021.145

Pág.: 35-51
Carlos Jesús González, et al.....

La Historia de Vida como técnica ...

\section{Conclusión}

Entender a la historia de vida como técnica cualitativa de recolección de datos en estudios sociales conlleva la admisión del imaginario sociológico como aquella competencia de actuar o servir como moderador entre el individuo, el relato biográfico y la historia devenida, es decir, las concepciones sociales. Conlleva así mismo el conceder el rol activo del individuo en la historia social producto de ese imaginario sociológico, "lo que el hombre hace de su destino en estas horas cruciales" (Veras, 2010, p. 150) a través de sus manifestaciones dentro del contexto social.

En esta técnica cualitativa, diversos elementos documentales, personales y sociales, reales o imaginarios, construidos con singular significancia, convergen entre sí. Por lo tanto, la memoria propia del individuo que relata sus experiencias debe entonces entenderse como una abstracción activa de significancias e afinidades interpretativas, estratégicamente elegidas, con la capacidad de directamente ejercer una influencia sobre el presente por medio de sus concepciones y creaciones sociales. Por ende, conduce hacia una reflexión expresada en una narración sobre la personal e individual verdad en relación con su contextual realidad social, que debe ser tratada de manera minuciosa, crítica y enriquecedora. El resultado obtenido entonces dependerá de la competencia desarrollada y el conocimiento generado por parte del investigador acerca de las limitaciones y potencialidades de la historia de vida aportan y contribuyen al desarrollo de la investigación biográfica en ciencias sociales (Sanz, 2005).

\section{Referencias}

Aguirre, J. Jaramillo, L. (2015). El papel de la descripción en la investigación cualitativa. Cinta de Moebio, 53, 175-189.

Arias, M. Betancurth, D. (2015). La experiencia de formación en investigación cualitativa. Revista Facultad Nacional de Salud Pública, 33 (1), 1-4.

Barba, J. Barba, A. González, G. (2015). De la domesticación de la investigación cualitativa al reto de reinventarse. Revista Científica Guillermo de Ockham, 13 (1), 51-58.

Berríos, R. (2000). La modalidad de la historia de vida en la metodología cualitativa. Paidea Puertorriqueña, 2(1), 1-17.

Birulés, F. (1995). Introducción, en Birulés, F. (Comp.), El género de la memoria, Pamplona: Pamiela.

Bonilla, E. (2005). Más allá del dilema de los métodos. La investigación en Ciencias Sociales. Bogotá: Grupo Editorial Norma. 
Año 16, Vol. 11, número 21, agosto-diciembre Sección: Ciencias Sociales

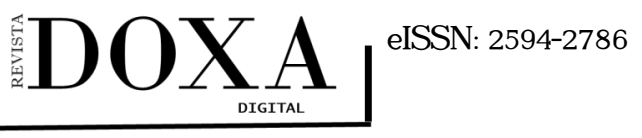

Pág.: 35-51
Carlos Jesús González, et al.....

DOI: $10.52191 /$ rdojs.2021.145 La Historia de Vida como técnica ...

Botto, A. (2011). Dimensión ética de la investigación cualitativa. Revista GPU, Psiquiatría Universitaria, 354-357.

Chárriez, M. (2012). Historias de vida: Una metodología de investigación cualitativa. Revista Griot, 5(1), 50-67.

Cornejo, M., Rojas, R. y Mendoza, F. (2008). La investigación con Relatos de Vida: Pistas y opciones del Diseño Metodológico. Psykhe, 17, 29-39.

Corona, J. (2018). Investigación Cualitativa: Fundamentos Epistemológicos, Teóricos y Metodológico. Vivat Academia, 144 (1). DOI: 10.15178/va.2018.144.69-76

De la Cuesta, C. (2015). Aprender el oficio de investigar cualitativamente: formarse un self indagador. Revista Facultad Nacional de Salud Pública, 33, 23-29.

Hernández, K. (2009). El método historia de vida: alcances y potencialidades. Recuperado el 08-05-2016 en: http:// www.gestiopolis.com/economia/metodo-de-investigación-cualitativa.htm.

Jones, G. (1983). Life history methodology. En G. Morgan (Ed.), Beyond Methods. California: Sage.

Martínez, C. (2015). El compromiso interpretativo: un aspecto ineludible en la investigación cualitativa. Revista Facultad Nacional de Salud Pública, 33 (1), 58-66.

Merlinsky, G. 2006. La Entrevista como Forma de Conocimiento y como Texto Negociado. Cinta de Moebio, 27, 27-33.

Moscoso, L. Díaz, L. (2018). Aspectos éticos en la investigación cualitativa con niños. Revista Latinoamericana de Bioética, 18 (1). DOI: https://doi.org/10.18359/rlbi.2955

Muratorio, B. (2005). Historia de vida de una mujer amazónica: intersección de autobiografía, etnografía e historia. Iconos. Revista de Ciencias Sociales, 21, 129-143.

Páramo, P., Otálvaro, G. (2006). Investigación Alternativa: Por una distinción entre posturas epistemológicas y no entre métodos. Cinta de Moebio, 25, 1-8.

Pourtois, J. (2005). Epistemología e instrumentación en ciencias humanas. Barcelona: Herder.

Pujadas, J. (2000). El método biográfico y los géneros de la memoria. Revista de Antropología Social, 9, 127-158.

Ruíz, J. (2012). Historias de vida. Metodología de la Investigación Cualitativa. Bilbao: Universidad de Deusto.

Ruiz, J. (2003). Metodología de la investigación cualitativa. Bilbao: Universidad de Deusto.

Sanmartín, R. (2003). Observar, escuchar, comparar, escribir. La práctica de la investigación cualitativa. Barcelona: Ariel Antropología. 
Año 16, Vol. 11, número 21, agosto-diciembre Sección: Ciencias Sociales DOXA
DOI: $10.52191 /$ rdojs.2021.145

Pág.: 35-51
Carlos Jesús González, et al.....

La Historia de Vida como técnica ...

Sanz, A. (2005). El método biográfico en investigación social: potencialidades y limitaciones de las fuentes orales y los documentos personales. Asclepio, 57(1), 99-115.

Taylor, S. (1998). Introducción a los métodos cualitativos de investigación la búsqueda de significados. Buenos Aires: Paidós.

Troncoso, C. Amaya, A. (2017). Entrevista: guía práctica para la recolección de datos cualitativos en investigación de salud. Revista de la Facultad de Medicina, 65 (2), 329-332. DOI: 10.15446/revfacmed.v65n2.60235.

Veras, E. (2010). Historia de Vida: ¿Un método para las ciencias sociales? Cinta moebio, 39, 142-152. 